Special Issue of the 6th International Congress \& Exhibition (APMAS2016), Maslak, Istanbul, Turkey, June 1-3, 2016

\title{
Electrical Conductivity and Corrosion Performances of In Situ and Ex Situ AA7075 Aluminum Composites
}

\author{
H.B. EREK ${ }^{a, *}$, D. ÖZYÜREK ${ }^{a}$ AND A. $\operatorname{ASAN}^{b}$ \\ ${ }^{a}$ Karabuk University, Technology Faculty, Manufacturing Engineering, 78100 Karabuk, Turkey \\ ${ }^{b}$ Hitit University, Faculty of Engineering, Chemical Eng., 19100 Corum, Turkey
}

\begin{abstract}
The present study investigates corrosion behaviors and electric conductivity of AA7075 in situ $\left(\mathrm{TiAl}_{3}\right)$ and ex situ $\left(\mathrm{B}_{4} \mathrm{C}\right)$ composites produced by powder metallurgy method. In production of in situ composites, various amounts of $\mathrm{Ti}(2,4$ and $6 \%)$ are added to AA7075 and for production of ex situ composites, $\mathrm{B}_{4} \mathrm{C}(3,6$, and $9 \%)$ are added. Prepared in situ and ex situ composite powders were pre-shaped at $600 \mathrm{MPa}$ pressure with cold pressing. Pre-shaped samples were sintered in the atmosphere-controlled furnace at $580^{\circ} \mathrm{C}$ for $4 \mathrm{~h}$. Corrosion test of produced composites was conducted in $0.1 \mathrm{M} \mathrm{H}_{2} \mathrm{SO}_{4}$ solution. As a result of these analyses, corrosion examinations on in situ manufactured composites revealed that anode and cathode currents are close to each other and those composites do not exhibit different corrosion behaviors. Corrosion rate of $\mathrm{B}_{4} \mathrm{C}$ added ex situ composites increases by $\mathrm{B}_{4} \mathrm{C}$ rate (due to increase of density of current).
\end{abstract}

DOI: 10.12693/APhysPolA.131.153

PACS/topics: $82.45 . \mathrm{Bb}$

\section{Introduction}

Aluminum and its alloys are second most widely used materials after iron-based alloys. Low strength of pure aluminum limits industrial use of this material. Therefore, alloying is used to improve properties of pure aluminum to use them for desired purposes [1,2]. Titanium is an element having a high strength/density ratio and resistance to high temperatures [3]. Al-Ti alloys are one of the most promising materials for the future applications. The distinctive properties of $\mathrm{Al}-\mathrm{Ti}$ alloys are resistive to oxidation and wear, having a good strength in high temperatures and low density. Therefore, these alloys are preferred in aerospace and automotive technology for engineering applications. The main problem for this alloys is low elongation capacity at room temperature. Low elongation capacity at room temperature is the biggest obstacle to the common use in applications [4]. $\mathrm{Al}$ alloys are used in automotive and aerospace industries due to its superior properties such as low density, easy forming, high electric conductivity, and corrosion resistance. Due to these superior properties, aluminum alloys are used in the production of metal-matrix composites. The most widely used ceramic reinforcement materials in the production of aluminum composite materials (ACMs) are $\mathrm{SiC}$ [5], $\mathrm{Al}_{2} \mathrm{O}_{3}[6], \mathrm{SiO}_{2}$ [7], $\mathrm{Si}_{3} \mathrm{~N}_{4}$ [8], AlN [9], $\mathrm{ZrB}_{2}$ [10], $\mathrm{TiB}_{2}$ [11], $\mathrm{B}_{4} \mathrm{C}$ [12], and $\mathrm{TiC}$ [13]. $\mathrm{B}_{4} \mathrm{C}$ is an attractive reinforcement material used in production of aluminum composites having low density, high rigidity and thermal stability [14]. Nevertheless, there are some problems preventing widely use of $\mathrm{Al}-\mathrm{B}_{4} \mathrm{C}$ composites, one of which is economic and the other one is

*corresponding author; e-mail: halitburakerek@gmail.com technical. In this study, corrosion behaviors and electric conductivity of in situ and ex situ produced, ACMs are investigated using AA7075 alloy added Ti (2-4 and 6\%) and $\mathrm{B}_{4} \mathrm{C}(3-9 \%)$ at various amounts (wt\%). Corrosion behaviors and electric conductivity characteristics of the ACMs produced by in situ and ex situ methods were compared in order to determine ideal compositions.

\section{Materials and method}

In the experimental studies, AA7075 alloy powder $(<100 \mu \mathrm{m})$ produced with the gas atomization method is used as matrix material. The chemical composition of matrix material is given in Table I.

TABLE I

Chemical composition of the AA7075 alloy used in the production of ACMs.

\begin{tabular}{c|c|c|c|c|c|c|c|c|c}
\hline \hline Element & $\mathrm{Zn}$ & $\mathrm{Mg}$ & $\mathrm{Cu}$ & $\mathrm{Fe}$ & $\mathrm{Si}$ & $\mathrm{Zr}$ & $\mathrm{Cr}$ & $\mathrm{Mn}$ & $\mathrm{Al}$ \\
\hline [wt\%] & 5.48 & 2.58 & 1.568 & 0.549 & 0.403 & 0.0305 & 0.125 & 0.014 & bal.
\end{tabular}

The ACMs are produced by adding 2-6\% Ti and 3$9 \% \mathrm{~B}_{4} \mathrm{C}$ into gas-atomized AA7075 alloy. After mixing the powder in Turbula Shaker Mixer (T2F Glenn Mills) $67 \mathrm{rev} / \mathrm{min}$ for $45 \mathrm{~min}$, it is cold-pressed under $600 \mathrm{MPa}$ pressure to produce cylindrical samples in dimensions of $\varnothing 12 \times 7 \mathrm{~mm}$. Produced green compacts are sintered at $580^{\circ} \mathrm{C}$ in an atmosphere-controlled (argon) environment for $4 \mathrm{~h}\left(10^{\circ} \mathrm{C} / \mathrm{min}\right)$ and then cooled down in furnace to the room temperature. Following standard metallographic processes, produced AMC samples are etched with $95 \mathrm{ml}$ distilled water, $2.5 \mathrm{ml} \mathrm{HNO}_{3}, 1.5 \mathrm{ml} \mathrm{HCl}$ and $1 \mathrm{ml} \mathrm{HF}$ (Keller's) solution for 15-20 s. Density measurements are conducted based on the Archimedes principles. Microstructures of produced in situ and ex situ aluminum composites are investigated with scanning 
electron microscopy (SEM) and energy dispersive X-ray spectroscopy (EDS). Tafel and impedance diagrams of samples prepared for corrosion tests are determined by platinum reference and operation electrodes in $0.1 \mathrm{M}$ $\mathrm{H}_{2} \mathrm{SO}_{4}$ solution. Regarding electrical conductivity measurements, electric resistance of in situ and ex situ composite samples are measured by placing a copper material. Results (IACS \%) are calculated according to the ASTM (B193-02) standard.

\section{Results and discussion}

\subsection{Microstructural characterization}

Figure 1 shows the microstructure SEM images of in situ and ex situ produced aluminum composites with powder metallurgy.

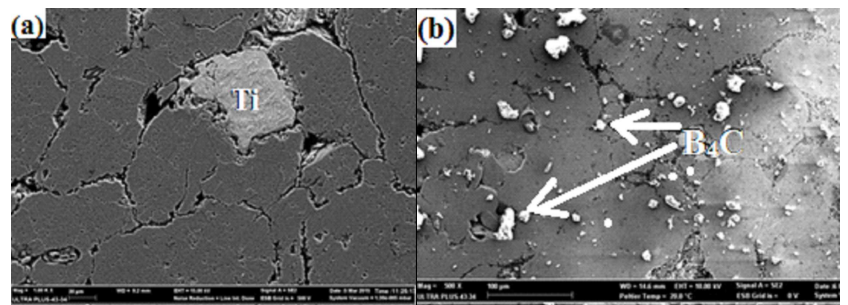

Fig. 1. SEM micro-structure images of ACMs in situ (a) and ex situ (b).

In the SEM image given in Fig. 1a it could be seen that titanium added into the structure in order to form in situ precipitates is seen as coarse grains in the matrix. Formation of in situ $\mathrm{TiAl}_{3}$ phase in the structure could be explained by $\alpha$-Al and $\mathrm{TiAl}_{3}$ structural transformations in the Al-Ti diagram. From the Al-Ti phase diagram, peritectic reaction occurs between $\mathrm{TiAl}_{3}$ intermetallic phase and aluminum. Titanium diffuses through $\mathrm{Al} / \mathrm{TiAl}_{3}$ borders to form strong mechanical bonds in these areas [15], whereas homogeneous distribution of $\mathrm{B}_{4} \mathrm{C}$ reinforcement material added into AA7075 alloy is observed from Fig. 1b. Figure 2 shows the XRD result of the in situ produced aluminum composite added $\mathrm{Ti}$ by $6 \%$.

XRD pattern in Fig. 2 shows that in situ $\mathrm{TiAl}_{3}$ phases are successfully formed in the structure. Besides $\mathrm{TiAl}_{3}$ phase, $\mathrm{Al}$ and $\mathrm{Ti}$ phases can be observed in the structure. Figure 3 gives the Tafel polarization diagram and polarization resistance values of added $\mathrm{Ti}$ (in situ), (a),(b) and $\mathrm{B}_{4} \mathrm{C}$ (ex situ) (c),(d) composites.

As it could be seen from the Tafel diagram of the composites produced by addition of different amounts of $\mathrm{Ti}$ into the AA7075 alloy, corrosion rates of in situ composites are determined as $0.556 \mathrm{~mm} /$ year $(2 \% \mathrm{Ti})$, $1.26 \mathrm{~mm} /$ year $(4 \% \mathrm{Ti})$ and $0.600 \mathrm{~mm} /$ year $(6 \% \mathrm{Ti})$, Fig. 3a. Aluminum's corrosion resistance against variety of environment is a result of amorphous or crystalline aluminum-oxide layer formed on the surface subject to current conditions. As purity of aluminum decreases, corrosion resistance decreases as well. Increase of

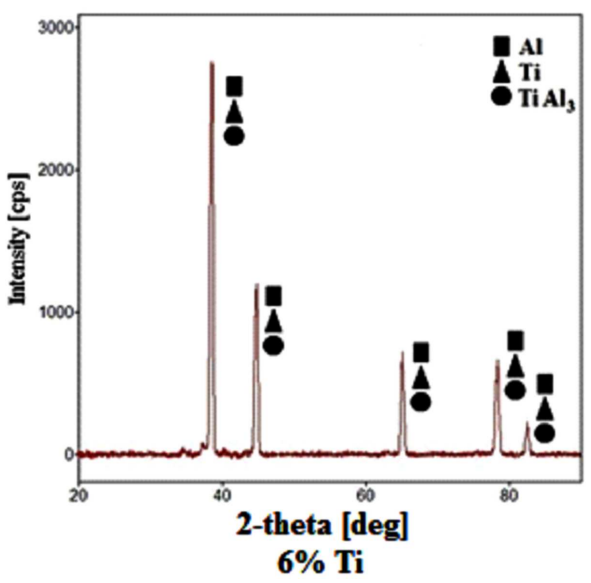

Fig. 2. XRD result of the in situ aluminium composite added $6 \% \mathrm{Ti}$.
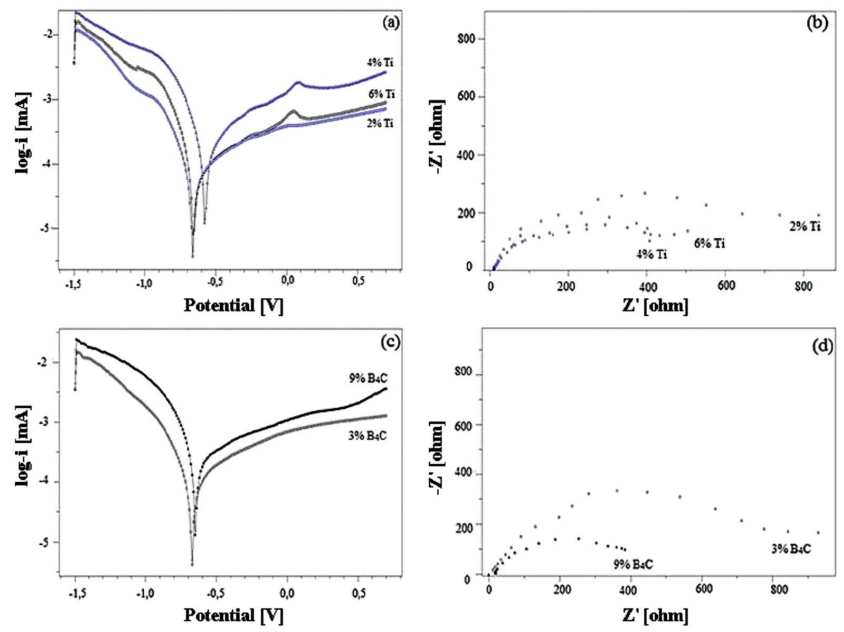

Fig. 3. Tafel polarization diagram and polarization resistances of composites added $\mathrm{Ti}$ (in situ) (a),(b) and $\mathrm{B}_{4} \mathrm{C}$ (ex situ) (c),(d).

impurities in the structure of material is the most significant factor in reduction of corrosion resistance. According to Fig. 3b, impedance measurements polarization resistance supports behavior of in situ composite containing $4 \% \mathrm{Ti}$ (as it was seen with the Tafel diagrams). Table II gives corrosion parameters obtained from the Tafel diagrams, density and electric conductivity results. Polarization resistances obtained from the measurement (Fig. 3d) are compatible with load transfer resistance values obtained from impedance measurements.

It is seen from Table II that density of in situ composites $(2 \% \mathrm{Ti})(4 \% \mathrm{Ti})$ and $(6 \% \mathrm{Ti})$ were measured as $2.647 \mathrm{~g} / \mathrm{cm}^{3}, 2.666 \mathrm{~g} / \mathrm{cm}^{3}$ and $2.732 \mathrm{~g} / \mathrm{cm}^{3}$, respectively. This result shows that as the amount of titanium added into the alloy increases, densities of in situ composites increase. The reason is that although the density of AA7075 alloy was $2.74 \mathrm{~g} / \mathrm{cm}^{3}$, density of added titanium is $4.52 \mathrm{~g} / \mathrm{cm}^{3}$. As the amount of Ti added into the alloy increases, density of produced composites increases as well. On the other hand, as the amount of $\mathrm{B}_{4} \mathrm{C}$ 
TABLE II

Corrosion parameters obtained from Tafel diagrams of composites use electrodes produced by addition of in situ (Ti) and ex situ $\left(\mathrm{B}_{4} \mathrm{C}\right)$ in $0.1 \mathrm{M} \mathrm{H}_{2} \mathrm{SO}_{4}$ solutions, density and electric conductivity results.

\begin{tabular}{c|c|c|c|c|c|c|c}
\hline \hline $\begin{array}{c}\text { Electrode } \\
\text { type }\end{array}$ & $\begin{array}{c}-E_{\mathrm{kor}} \\
{[\mathrm{mV}]}\end{array}$ & $\begin{array}{c}R_{p} \\
{[\Omega]}\end{array}$ & $\begin{array}{c}-\beta_{a} \\
{[\mathrm{mV}]}\end{array}$ & $\begin{array}{c}-\beta_{c} \\
{[\mathrm{mV}]}\end{array}$ & $\begin{array}{c}\text { Cor. rate } \\
{[\mu \mathrm{m} / \text { year }]}\end{array}$ & $\begin{array}{c}\text { Density } \\
{\left[\mathrm{g} / \mathrm{cm}^{3}\right]}\end{array}$ & $\begin{array}{c}\text { Electrical } \\
\text { conduct. } \\
{[\mathrm{IACS} \%]}\end{array}$ \\
\hline $2 \% \mathrm{Ti}$ & 0.6969 & 869.2 & 0.601 & 0.142 & 0.556 & 2.647 & 3.18 \\
$4 \% \mathrm{Ti}$ & 0.6139 & 363.1 & 0.515 & 0.127 & 1.260 & 2.666 & 2.84 \\
$6 \% \mathrm{Ti}$ & 0.6660 & 513.0 & 0.527 & 0.081 & 0.600 & 2.732 & 2.25 \\
$3 \% \mathrm{~B}_{4} \mathrm{C}$ & 0.7069 & 540.9 & 0.873 & 0.168 & 1.107 & 2.732 & 10.5 \\
$9 \% \mathrm{~B}_{4} \mathrm{C}$ & 0.6550 & 209.3 & 0.826 & 0.147 & 2.690 & 2.629 & 3.60
\end{tabular}

added into the AA7075 alloy increases, densities of produced ex situ composites tend to decrease. As for electric conductivity of in situ and ex situ produced composites, increasing amount of reinforcement phase decreases the electrical conductance (IACS\%) in ex situ aluminum composites produced by addition of different amounts of (3-9\%) $\mathrm{B}_{4} \mathrm{C}$. IACS\% value of the in situ aluminum composites decreases as the amount of $\mathrm{Ti}$ added into the $e x$ situ composite increases. These results are expected from the electrical conductivity tests. It is related with a number of microstructural factors such as electrical conductivity or electrical resistance of metallic materials. These are effective on dimension and volume ratio, pores, lattice defects and precipitates within the structure of metallic materials. IACS\% values obtained from the experimental studies suggest that homogeneity of microstructure, amount and size of reinforcement materials added are effective on electrical conductivity.

\section{Conclusion}

It can be concluded from the microstructure investigations of the composites produced by adding $\mathrm{Ti}$ and $\mathrm{B}_{4} \mathrm{C}$ into gas-atomized AA7075 alloy powders that reinforcement materials exhibit a homogeneous distribution in the structure. XRD investigations show that $\mathrm{TiAl}_{3}$ phase occurred in the structure of the in situ composites produced by adding different amounts of Ti. Because of density difference, as the amount of reinforcement material added into the alloy increases, density of in situ composites increases as well. Such a situation decreases density of ex situ composites. Similar currents measured at anode and cathode during corrosion investigations of in situ composites suggest that composites do not have different corrosion behaviors. On the other hand, as $\mathrm{B}_{4} \mathrm{C}$ amount increases in ex situ composites containing $\mathrm{B}_{4} \mathrm{C}$, corrosion rate (occurrence of current density) increases as well.

\section{References}

[1] D. Özyürek, R. Yllmaz, E. Kibar, J. Fac. Eng. Archit. Gaz. 27, 193 (2012).

[2] R. Yılmaz, D. Özyürek, E. Kibar, J. Fac. Eng. Archit. Gaz. 27, 429 (2012).

[3] K.M. Il, K.S. Lee, J. Alloys Comp. 264, 258 (1998).

[4] H. Zhao, J. Wang, Y. Song, S. Guan, Trans. Nonferrous Met. Soc. China 20, 751 (2010).

[5] R.N. Rao, S. Das, Mater. Des. 31, 1200 (2010).

[6] A.M. Al-Qutub, I.M. Allam, M.A.A. Samad, J. Mater. Sci. 43, 5797 (2008).

[7] K.H.W. Seah, J. Hemanth, S.C. Sharma, Mater. Des. 24, 87 (2003).

[8] C.S. Ramesh, R. Keshavamurthy, Mater. Des. 32, 1833 (2011)

[9] B.A. Kumar, N. Murugan, Mater. Des. 40, 52 (2012).

[10] I. Dinaharan, N. Murugan, Trans. Nonferrous Met. Soc. China 22, 810 (2012).

[11] S. Kumar, M. Chakraborty, V.S. Sarma, B.S. Murty, Wear 265, 134 (2008).

[12] F. Tag, X. Wu, S. Ge, J. Ye, H. Zhu, M. Hagiwara, J.M. Schoenung, Wear 264, 555 (2008).

[13] S. Gopalakrishnan, N. Murugan, Composites Part B 43, 302 (2012).

[14] K. Uenishi, T. Matsubara, M. Kambara, K.F. Kobayashi, Scr. Mater. 44, 2093 (2001).

[15] D. Özyürek, T. Tuncay, H. Evlen, İ. Çiftçi, Mater. Res. 18, 813 (2015). 